\title{
First imaging and identification of a noctilucent cloud from multiple sites in Hokkaido $\left(43.2-44.4^{\circ} \mathrm{N}\right)$, Japan
}

\author{
Hidehiko Suzuki ${ }^{*}$ (D), Kazuyo Sakanoi ${ }^{2}$, Nozomu Nishitani ${ }^{3}$, Tadahiko Ogawa ${ }^{4}$, Mitsumu K. Ejiri ${ }^{5}$, Minoru Kubota ${ }^{4}$,
} Takenori Kinoshita ${ }^{6}$, Yasuhiro Murayama ${ }^{4}$ and Yasushi Fujiyoshi ${ }^{7}$

\begin{abstract}
Simultaneous imaging observations of a noctilucent cloud (NLC) from five sites in Hokkaido, Japan (43.17-45.36 $\mathrm{N}$ ), were successfully carried out using digital cameras in the early hours of the morning (around 02:00 LST) on June 21, 2015. This is the first NLC event that has been captured from multiple sites in Japan. The simultaneous images obtained from multiple sites made it possible to calculate the exact altitude $(=83.9 \pm 0.1 \mathrm{~km})$ and spatial distribution $\left(47.5-50.0^{\circ} \mathrm{N}\right.$ and $\left.143.0-147.5^{\circ} \mathrm{E}\right)$ of the NLC by triangulation and image correlation methods. Based on a comparison of atmospheric parameters of the upper mesosphere provided by satellites and a middle-frequency (MF) radar in northern Hokkaido (Wakkanai) with the cloud distribution obtained from the Aeronomy of Ice in the Mesosphere satellite, this particular event is considered to be the result of southward advection of the NLC from a higher-latitude (i.e., colder) region. Anomalies in the upper mesospheric temperature of the northern hemispheric summer in 2015 were examined using AURA satellite data, because this is the first NLC event that has been identified in Japan. However, no remarkable temperature variations relative to other years were found in upper mesosphere. Based on a comparison between the NLC period and the record of sky conditions archived by the Japan Meteorological Agency, a high percentage of cloud (especially low-level) cover during the summer in Hokkaido cannot be ruled out as a possible reason why the NLC had not previously been sighted in Hokkaido.
\end{abstract}

Keywords: Noctilucent cloud, NLC, Hokkaido Japan, Upper mesosphere

\section{Introduction}

The occurrence of noctilucent clouds (NLCs) is considered to be caused by enhancement of low temperature and high humidity in the upper mesosphere, which is closely related to an increase of greenhouse gases, $\mathrm{CO}_{2}$ and $\mathrm{CH}_{4}$. Studies of NLC variation and transportation mechanisms have been widely conducted and are expected to contribute to a better understanding of the effects of global climate change on the upper mesosphere. In 2007, NASA launched the Aeronomy of Ice in the Mesosphere (AIM) satellite to monitor the polar mesospheric clouds (PMCs) (Russell et al. 2009), which are presumed to be phenomena identical to NLCs. The AIM

\footnotetext{
*Correspondence: suzuhide@meiji.ac.jp

${ }^{1}$ Meiji University, Kawasaki, Kanagawa, Japan

Full list of author information is available at the end of the article
}

satellite, which is still in operation, provides data regarding the temporal and spatial variations of PMCs over both polar regions (latitudes $>60^{\circ}$ ). NLCs have also been observed in middle-latitude regions. For example, Taylor et al. (2002) reported an NLC event at Logan, Utah, USA $\left(41.7^{\circ} \mathrm{N}\right)$, in June 1999 . Other examples are found in the NLC photo gallery of spaceweather.com (http://spaceweather.com/nlcs/gallery2009_page1.htm). This archive shows great enhancement of the occurrence of NLCs, particularly in July 2009. During this period, NLCs were sighted as far south as Colorado $\left(39^{\circ} \mathrm{N}\right)$, Virginia, and many countries in Europe.

Although there have not been any convincing reports of NLCs in Japan, the occurrence of NLCs in Hokkaido is considered to be possible, similar to other middlelatitude regions, because strongly related phenomena, such as mesosphere summer echoes (MSEs), have been 
frequently observed by very high-frequency (VHF) radar in Wakkanai $\left(45.4^{\circ} \mathrm{N}\right)$ (Ogawa et al. 2011). These results also support the potential occurrence of NLCs in Hokkaido, Japan. Because the dynamics that can explain the behavior of NLCs are not completely understood, it is important to monitor the occurrence and distribution of NLCs in the middle-latitude regions using ground-based observations.

In order to monitor the occurrence of NLCs, a network of digital cameras has been installed in Hokkaido, Japan, since June 2010. The cameras enable several research groups from Japanese institutes and universities to monitor NLCs in the middle-latitude region of Japan. This paper examines the parameters of an NLC determined by a prompt analysis of the NLC images captured in the early morning of June 21,2015 , from multiple locations in Hokkaido.

The details of our camera system and the NLC event on June 21 are described in "Instrumentation and data" section. The image processing procedures used to deduce the altitude and spatial distribution of the NLC from simultaneous images from two different locations and the subsequent results are described in "Analysis and results" section. Then, a mechanism to explain this single NLC event is suggested by comparing the atmospheric parameters of the upper mesosphere provided by satellites (AURA and AIM) and medium-frequency (MF) radar in "Discussion" section. Because this event is the first report of an NLC appearance in Japan, the reason why NLC events had not previously been captured in Hokkaido is also discussed in that section.

\section{Instrumentation and Data}

In 2010, the Mesosphere, Thermosphere and Ionosphere (MTI) research group in Japan started construction of a network of color digital cameras to monitor the lowlatitude aurora and NLCs in Hokkaido, located in the northernmost part of Japan. Five automated camera systems have been installed and are operating at the Wakkanai and Sarobetsu radar sites (hereafter WAK and SAR, respectively) operated by the National Institute of Information and Communications Technology (NICT), the Moshiri and Rikubetsu observatories (hereafter, MOS and RIK) operated by Nagoya University and the Nayoro observatory (hereafter, NYR) in Hokkaido. The first detections of an NLC from multiple locations in Japan were successfully achieved at three sites (MOS, NYR and RIK) on June 21, 2015. At the WAK and SAR sites, the NLC was not recognized because of low-level cloud and fog at that time. Additional NLC photographs simultaneously taken from two other locations in Hokkaido were reported and provided for this study. One set was taken by a professional photographer, Mr. Masamichi Shisa, in Otaru, Hokkaido (hereafter, OTR), and the other set was captured by an automated camera system for sea-ice and weather monitoring at Mt. Oyama in Monbetsu (hereafter, MON), operated by the Institute of Low Temperature Science (ILTS), Hokkaido University. Geographical locations, details of the imaging systems and NLC occurrence periods for each site are summarized in Table 1. It should be noted that the shooting intervals and timings were not uniform across the sites. Locations and fields of view (FOVs) of the cameras are shown in Fig. 1. The FOVs shown in this plot are estimated by assuming that the altitude of a subject was $85 \mathrm{~km}$ with no obstacles (e.g., trees, mountains, buildings) over the horizon. Only the FOV at OTR was not fixed because photographs were taken manually by a professional photographer.

Figure 2 shows highlights of the NLC photographs taken at each site. A luminous cloud with a peculiar color in the twilight sky is recognizable in all images. Wavelike structures similar to ripple structures, which are frequently seen in airglow images (e.g., Taylor and Hapgood 1990), are clearly seen in the images from MON, RIK and OTR. These appearances are consistent with typical NLC events reported elsewhere. Triangulation and image correlation methods were applied to calculate the exact altitude and spatial distribution of the NLC from the images. In the next section, the details and results of the analyses are described.

\section{Analysis and results}

As mentioned in the previous section, the timing of the photographs slightly differed between the five sites. However, some images were nearly simultaneous, with time stamps differing by no more than $30 \mathrm{~s}$. The NLC images taken in MON at 02:30:13 LST (Fig. 3a, image M) and RIK at 02:29:54 LST (Fig. 3b, image R) were selected as the best data for triangulation to estimate the altitude of the luminous cloud. In both cloud images, similar wavelike structures are clearly seen in the western edge of the whole cloud feature. Hereafter, these areas are defined as region $\mathrm{A}$ and are indicated by the small red rectangle in Fig. 3a, b. These areas in the cloud images are assumed to be the same feature and are used in the triangulation analysis.

A local horizontal coordinate (azimuthal and elevation angles) is determined using the known stars captured in the images. The procedure to determine the horizontal coordinates for each pixel using known star images is described in Suzuki et al. (2015). The difference from the original procedure is that lens distortion is considered in the present analysis. Five known stars at various distances from an image center are selected to estimate 
Table 1 Summary of instruments and observation sites for the NLC event on June 21, 2015

\begin{tabular}{|c|c|c|c|c|}
\hline Site name (abbreviation) & Location & Instruments (camera system) & $\begin{array}{l}\text { Period of NLC detection } \\
\text { HH:MM:SS in local standard } \\
\text { time (LST }=U T+9 \mathrm{~h}) \text { [shoot- } \\
\text { ing interval (min)] }\end{array}$ & Weather condition and remarks \\
\hline Nayoro (NYR) & $44.37^{\circ} \mathrm{N}, 142.48^{\circ} \mathrm{E}$ & Nikon D90 +F\#2.8/f = 15 mm & 02:23:07-02:38:07LST (5 min) & $\begin{array}{l}\text { Clear. Most of the structure is hid- } \\
\text { den by a mountain }\end{array}$ \\
\hline Moshiri (MSR) & $44.37^{\circ} \mathrm{N}, 142.27^{\circ} \mathrm{E}$ & Nikon D90 +F\#2.8/f = 10 mm & 02:09:55-02:17:55LST (3 min) & $\begin{array}{l}\text { Partly cloudy and foggy. Most } \\
\text { of the structure is hidden by a } \\
\text { mountain }\end{array}$ \\
\hline Monbetsu (MON) & $44.34^{\circ} \mathrm{N}, 143.32^{\circ} \mathrm{E}$ & Nikon D300S +F\#4/f $=12 \mathrm{~mm}$ & 02:00:13-02:45:13LST (15 min) & Clear \\
\hline Rikubetsu (RIK) & $43.53^{\circ} \mathrm{N}, 143.61^{\circ} \mathrm{E}$ & Nikon D700 +F\#2.8/f = 20 mm & 01:54:54-02:34:54LST (5 min) & $\begin{array}{l}\text { Clear. Some images are saturated } \\
\text { due to bright twilight sky }\end{array}$ \\
\hline Otaru (OTR) & $43.17^{\circ} \mathrm{N}, 140.97^{\circ} \mathrm{E}$ & Canon EOS 7D +F\#8/f $=35 \mathrm{~mm}$ & 02:14:**-02:40:**LST (Manual) & $\begin{array}{l}\text { Clear. Data provided by Mr. } \\
\text { Masamichi Shisa (photographer) }\end{array}$ \\
\hline
\end{tabular}

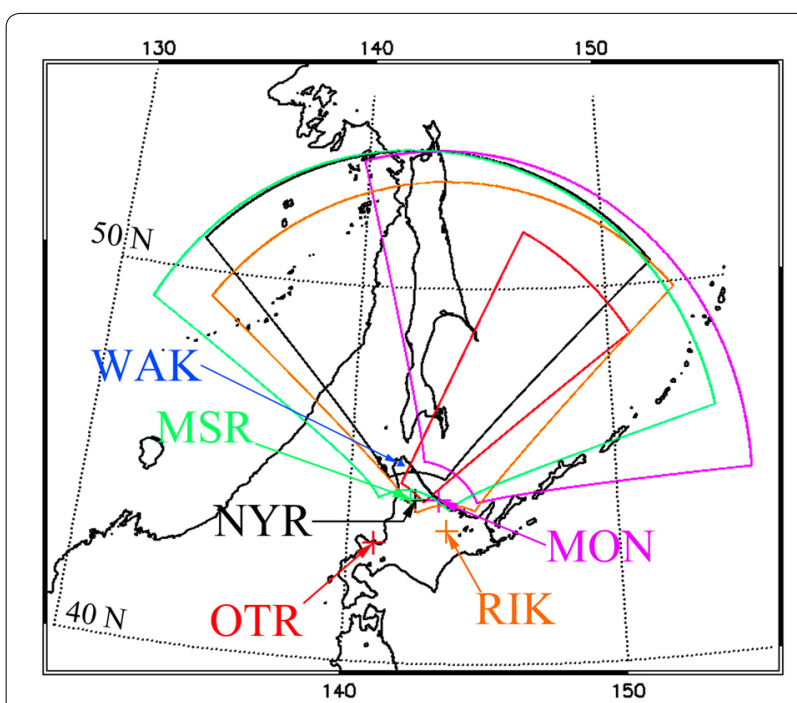

Fig. 1 Locations and fields of view (FOVs) of cameras at five sites in Hokkaido. FOVs shown in this figure are estimated by assuming the altitude of a cloud layer to be $85 \mathrm{~km}$ with no obstacles (e.g., trees, mountains, buildings) over the horizon. The blue triangle shows the location of Wakkanai VHF and MF radars

the distortion of the lens and horizontal coordinates. The horizontal coordinates embedded in Fig. 3 are determined using this procedure. The accuracies of the fitted coordinate system are within $0.3^{\circ}$ and $0.1^{\circ}$ for images $M$ and $R$, respectively. The larger uncertainty in the accuracy for the image taken from $\mathrm{MON}$ is due to slightly outof-focus star images.

The cloud images are projected on a geographical map by assuming their altitudes and using the given local horizontal coordinates. In this projection, the vertical extent of the cloud structure is assumed to be negligible. After the projection, a correlation coefficient between region A in both images is calculated $\operatorname{as} r_{z}=\frac{\sum_{i}\left(c_{M i}-\bar{c}_{M}\right)\left(c_{R i}-\bar{c}_{R}\right)}{\sqrt{\sum_{i}\left(c_{M i}-\bar{c}_{M}\right)^{2}} \sqrt{\sum_{i}\left(c_{R i}-\bar{c}_{R}\right)^{2}}}$, where $\Sigma_{i}$ is the summation of all overlapped pixels, $c_{M i}$ and $c_{R i}$ are the digital counts of the $i$-th overlapped pixel, and $\bar{c}_{M}$ and $\bar{c}_{R}$ are the averaged digital counts over $i$. The projected color images were converted to grayscale images, and the background trends were removed by subtracting smoothed data from the grayscale images to enhance cloud shapes before the coefficient $r_{z}$ calculation. The above procedure was repeated to obtain $r_{z}$ for each altitude by changing the assumed altitude between $z=75$ and $95 \mathrm{~km}$ by $0.1-\mathrm{km}$ step. Then, the altitude giving the maximum $r_{z}$ is defined as the altitude of the luminous cloud, $Z_{\mathrm{s}}$. Figure 4 shows the calculated correlation coefficients for each assumed altitude between 75 and $95 \mathrm{~km}$. In this case, $Z_{\mathrm{s}}$ is deduced as $83.9 \pm 0.1 \mathrm{~km}$, which is consistent with a typical altitude of an NLC (e.g., Gadsden and Schröder 1989). Therefore, the luminous cloud is robustly identified as an NLC. Figure 5 shows projected images of $M$ and $R$ with the assumed altitude $Z_{\mathrm{s}}$. Very robust agreement in spatial distribution is found between the two NLC images, not only for region A but also for the whole NLC structure. This agreement is also confirmed for NLC images taken from the other three sites (not shown). The latitudinal and longitudinal extents of the NLC are from 47.5 to $50.0^{\circ} \mathrm{N}$ and from 143.0 to $147.5^{\circ} \mathrm{E}$, respectively, at $02: 30$ LST.

\section{Discussion}

The luminous cloud on June 21, 2015 (local time), was robustly identified as an NLC by the triangulation method applied to the images from multiple sites. This event is the first report of an NLC appearance in Japan. However, the lowest latitude of the NLC distribution for the event, $\sim 47.5^{\circ} \mathrm{N}$ (see Fig. 5), was not extremely low relative to previous reports (e.g., Taylor et al. 2002). Other 


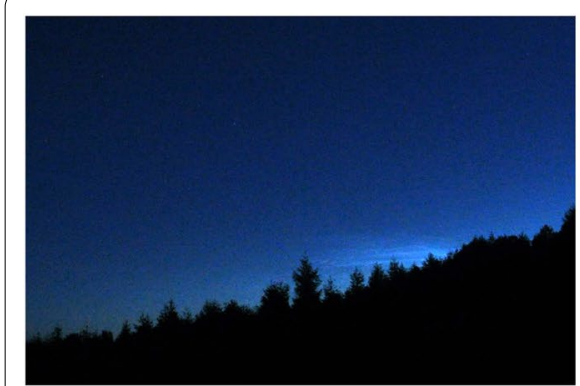

a Nayoro 02:26:07 LST

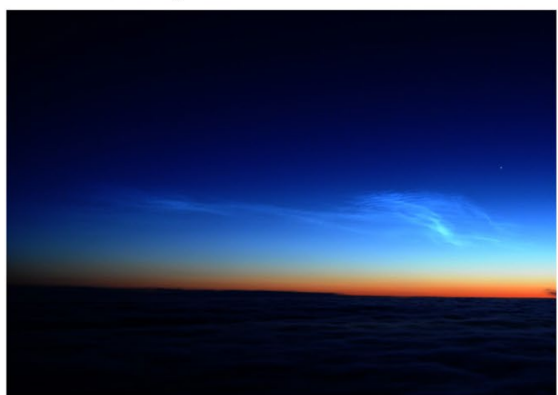

c Monbetsu 02:30:13 LST

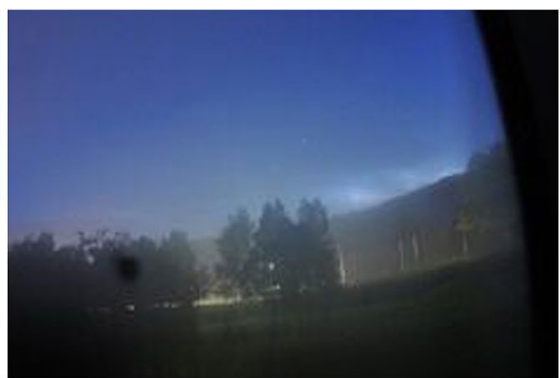

b Horokanai 02:15:55 LST

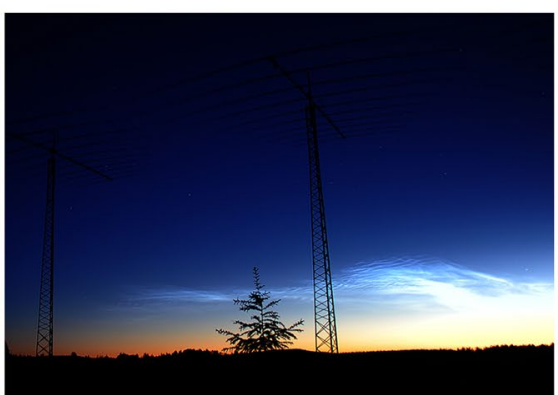

d Rikubetsu 02:24:54 LST

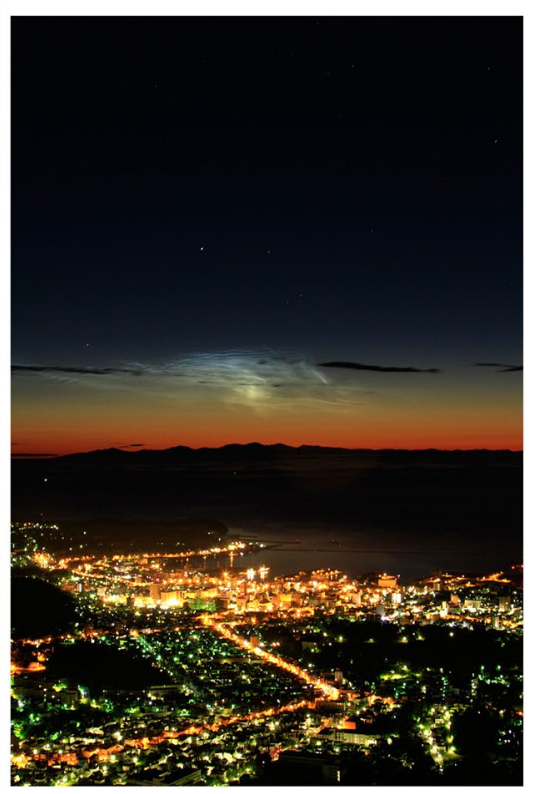

e Otaru $02: 27: * *$ LST

Fig. 2 Selected photographs of the NLC taken from a Nayoro, b Horokanai, c Monbetsu, d Rikubetsu, and e Otaru in Hokkaido in the early hours of morning on June 21, 2015. It is noted that uncertainty exists in the shooting time of the photograph (e) because the image was not taken for a scientific purpose at that time. The notation "**" in time code represents this uncertainty

\section{a Monbetsu 02:30:13 LST}

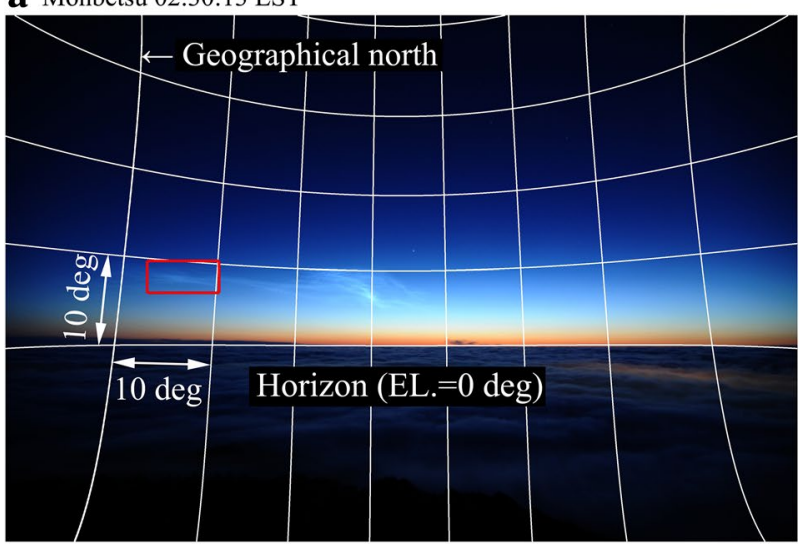

\section{b Rikubetsu 02:29:54 LST}

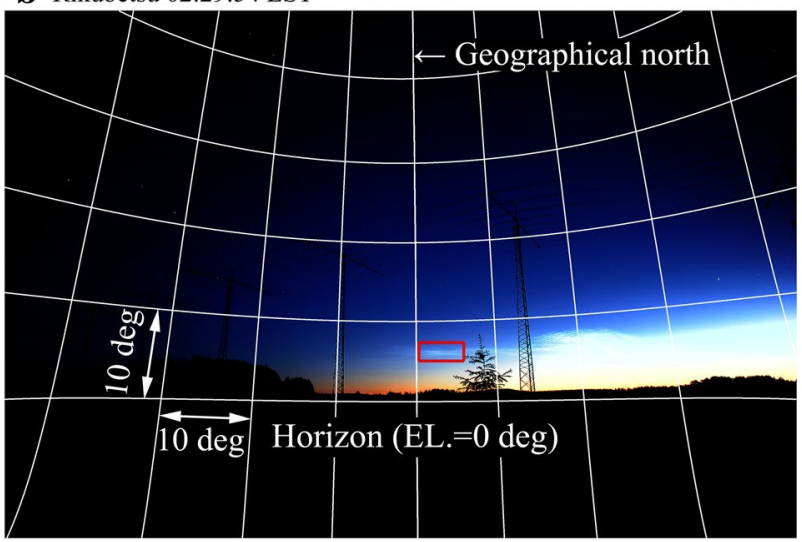

Fig. 3 Horizontal coordinates embedded on images a M (Monbetsu) and b R (Rikubetsu) by the procedure introduced in Suzuki et al. (2015)

witnesses or photographs of the NLC could have existed before this event, because the city of Wakkanai in the northernmost part of Hokkaido has a moderate population (more than 37,000 people). We next examine the anomalies of the mesospheric climate in the summer season of 2015 in the northern hemisphere.

Figure 6 shows atmospheric temperatures measured by the microlimb sounder onboard the AURA satellite
(AURA/MLS version 3.3 data) (Schwartz et al. 2008) at an altitude of $0.046 \mathrm{hPa}(\sim 86 \mathrm{~km})$ above $48^{\circ} \mathrm{N}, 145^{\circ} \mathrm{E}$ (the NLC region in the event). Each symbol in Fig. 6 corresponds to a single sounding taken over a tangential point within $200 \mathrm{~km}$ of $48^{\circ} \mathrm{N}, 145^{\circ} \mathrm{E}$ for each swath. In this figure, all data taken between 2011 and 2015 that satisfy the above criteria are plotted. Only the data taken in 2015 are indicated by colored symbols for easier comparison. The 


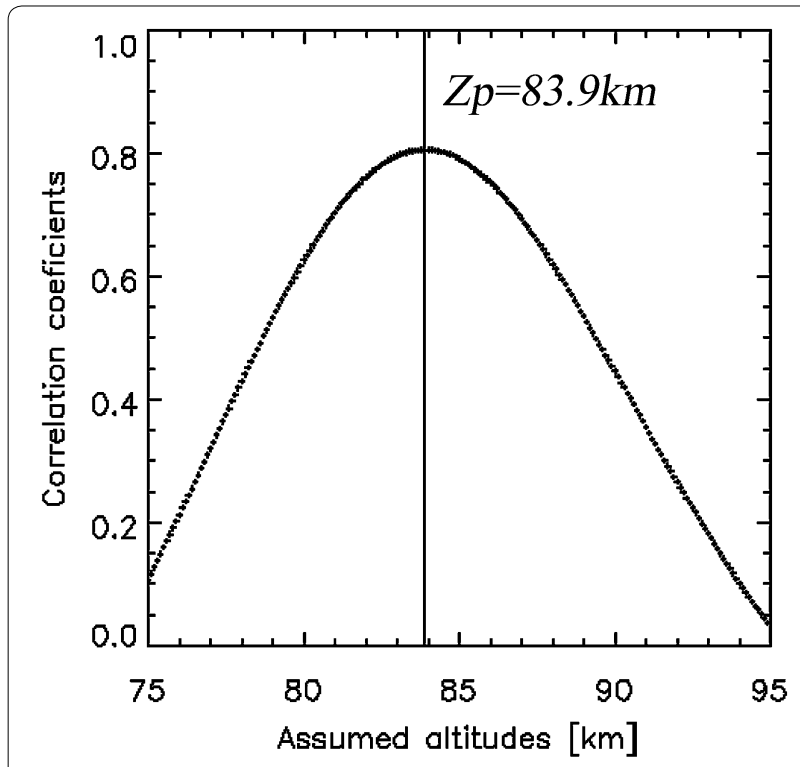

Fig. 4 Calculated cross-correlation coefficients as a function of assumed altitude between 75 and $95 \mathrm{~km}$. Vertical line indicates the altitude $Z_{\mathrm{s}}=83.9 \mathrm{~km}$ that yields the maximum correlation coefficient

vertical dashed line shows the day of year, DOY $=172$ (June 21, 2015), which corresponds to the day of the NLC event in 2015. Based on the lowest temperature and the timing of the summer decrease of temperature, no remarkable anomalies in the seasonal variation of the mesopause temperature were seen in 2015. This fact suggests that (1) the formation of the NLC was triggered by a local small-scale gravity wave with a large amplitude that was not detected by satellite observation, or (2) the formation occurred at a higher-latitude (i.e., colder) area and the NLC was transported by a southward wind to the observed point. The first possibility is difficult to confirm because of the lack of data that can be used to infer the spatial distribution of small-scale disturbances in the mesopause temperature at that time. The second possibility was examined using wind data observed by the MF radar operated by NICT in Wakkanai $\left(45.36^{\circ} \mathrm{N}\right.$, $\left.141.81^{\circ} \mathrm{E}\right)$.

Figure 7 shows the 30 -min averaged meridional wind (v) at an altitude of $84 \mathrm{~km}$ with an interval of $2 \mathrm{~km}$ (vertical resolution of $7 \mathrm{~km}$ ) in altitude. The duration of the southward wind before the NLC event was greater than $6 \mathrm{~h}$. The averaged meridional wind velocity during this period was $-25 \mathrm{~m} / \mathrm{s}$. This suggests that an air parcel located above Wakkanai at the time of the NLC event was transported by a southward wind from an area located $>540 \mathrm{~km}$ north. The area corresponds to a latitude of $>53^{\circ} \mathrm{N}$, which is sufficiently colder than the frost point for NLC formation ( $<140 \mathrm{~K}$ ) according to AURA/ MLS data (not shown). The presence of a polar mesospheric cloud (PMC) around $60^{\circ} \mathrm{N}$ during the day (June 20 ) is also evident in the daily albedo map observed by the cloud imaging and particle size (CIPS) instrument onboard the AIM satellite. Figure 8 shows the composed albedo map (Level 3a data) of the PMC in the northern

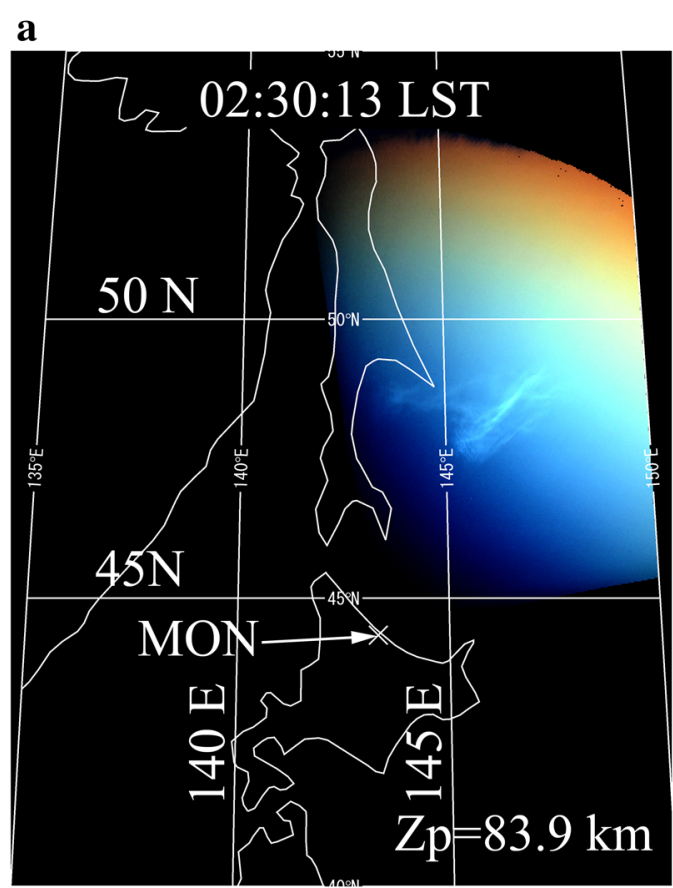

b

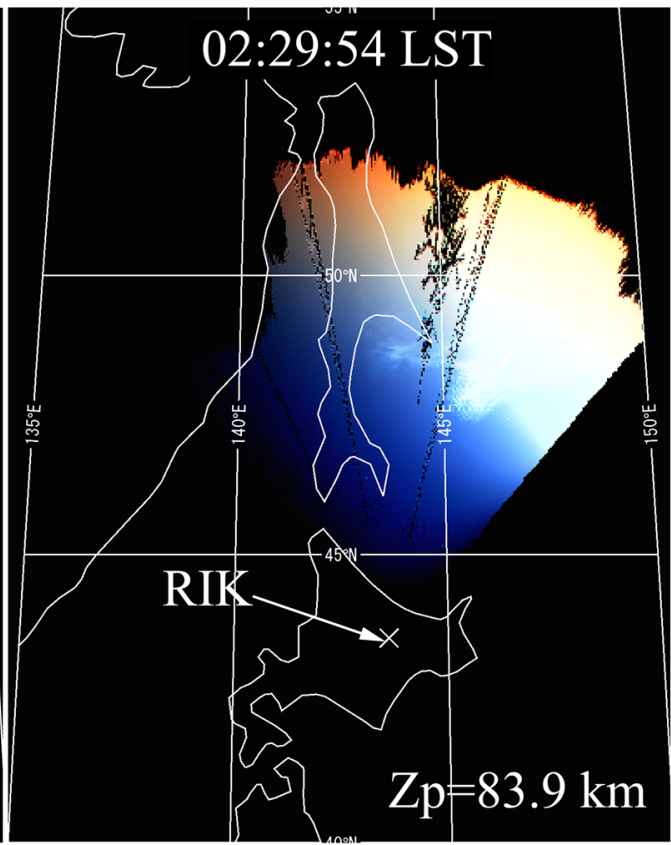

Fig. 5 Projected images (a image $M$ and $\mathbf{b}$ image $R$ ) with the assumed altitude $Z_{s}$ 


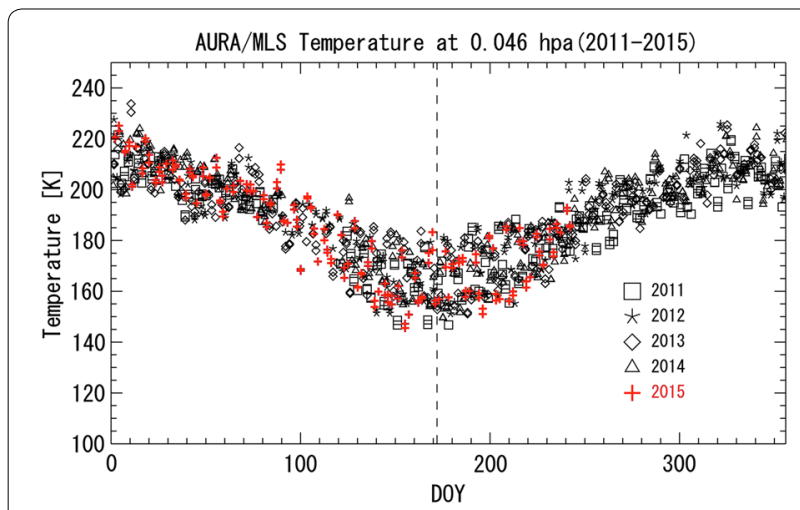

Fig. 6 Atmospheric temperatures measured by the microlimb sounder onboard the AURA satellite (AURA/MLS version 3.3 data) at an altitude of $0.046 \mathrm{hPa}(\sim 86 \mathrm{~km})$ above $48^{\circ} \mathrm{N}, 145^{\circ} \mathrm{E}$ (the $\mathrm{NLC}$ region in the event). The vertical dashed line shows DOY $=172$ (June 21, 2015)

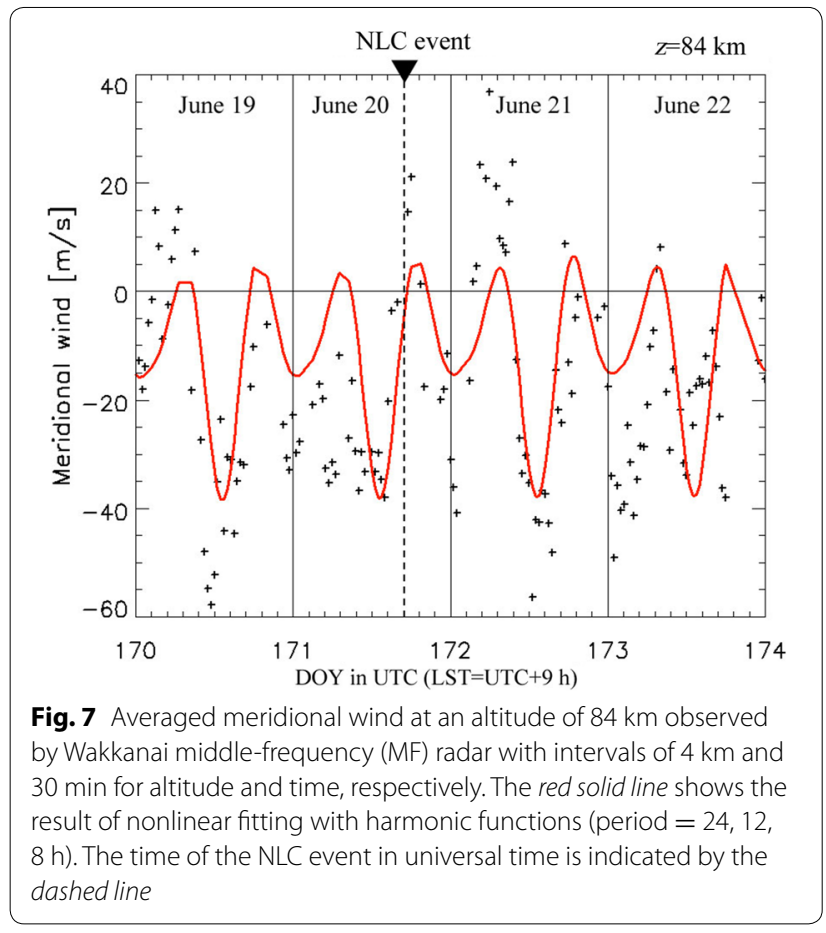

polar region observed by AIM/CIPS on June 20 (UT). The PMC expanding to $\sim 60^{\circ} \mathrm{N}$ circle is clearly seen at longitudes corresponding to the Far East Asia. These facts are consistent with "the transport scenario" to explain the cause of the NLC event.

Such a situation in the wind field is not unusual during this season because the dominant components of the wind field are periodic tidal winds. The red solid line shown in Fig. 7 is the result of a nonlinear least squares fitting of harmonic functions with periods of 8,12 and $24 \mathrm{~h}$ with respect to the meridional wind. The details of this fitting procedure are described in Kinoshita et al. (2015). This result shows the existence of nearly periodic transportation of the air parcel from the north to the south during this period. Gerding et al. (2007) suggested that advection of the NLC from higher-latitude regions is one of the important mechanisms for occurrences of the NLC in subpolar regions. They showed that detections of an NLC using a lidar system in Kühlungsborn $\left(54^{\circ} \mathrm{N}\right)$ between 2003 and 2005 (five events) always followed continuous southward winds at NLC altitudes. However, cases without NLC despite suitable conditions for NLC formation and advection were more frequent (i.e., temperature colder than the frost point with a southward wind). For example, meridional winds around 12:00 UT (LST-9 h) were southward during the subsequent 4 days, and the velocity was greater on July 19 and 21 than that on the event day. Such condition is considered to be more favorable for NLC transportation from polar region. However, no NLCs were sighted on these days. Therefore, a continuous southward wind is likely to be just a necessary but not a sufficient condition for NLC detections in middle-latitude regions.

Another possible reason that explains why the NLC had not been previously sighted in Hokkaido is simply the bad weather conditions during the NLC season. Low clouds or heavy fog in the Hokkaido area may have hidden the NLC from ground observers, even though NLCs are constantly transported to middle-latitude regions. The possibility of constant transportation of an NLC is supported by frequently observed MSEs by the VHF radar at Wakkanai (Ogawa et al. 2011). MSEs and polar MSEs (PMSEs) are known as phenomena strongly related to NLCs and are frequently observed simultaneously in high-latitude regions (e.g., von Zahn and Bremer 1999). The number of MSE events detected by the VHF radar during the summer season reached 65 events between June 2009 and September 2015. The weather records in Wakkanai during this period are available from a Web page of the Japan Meteorological Agency (JMA; http:// www.jma.go.jp/jma/index.html, accessed March 31, 2016). The record of the cloud cover (the proportion of the whole sky covered by clouds, expressed as a number from 0 to 10) were manually determined by trained JMA staff at twilight times (3:00 LST and 21:00 LST) on the days of MSE events. As a result of this comparison, $13.8 \%(10.8 \%)$ of morning (night) twilight times were clear (cloud cover <3) on the days of MSE events from 2009 to 2015. Therefore, the number of days on which an NLC could be seen with a relatively high possibility was only 7-9 days out of 5 years. This fact cannot rule out the possibility of bad weather as an explanation of why NLCs had not been captured in Hokkaido before the event reported in this paper. 


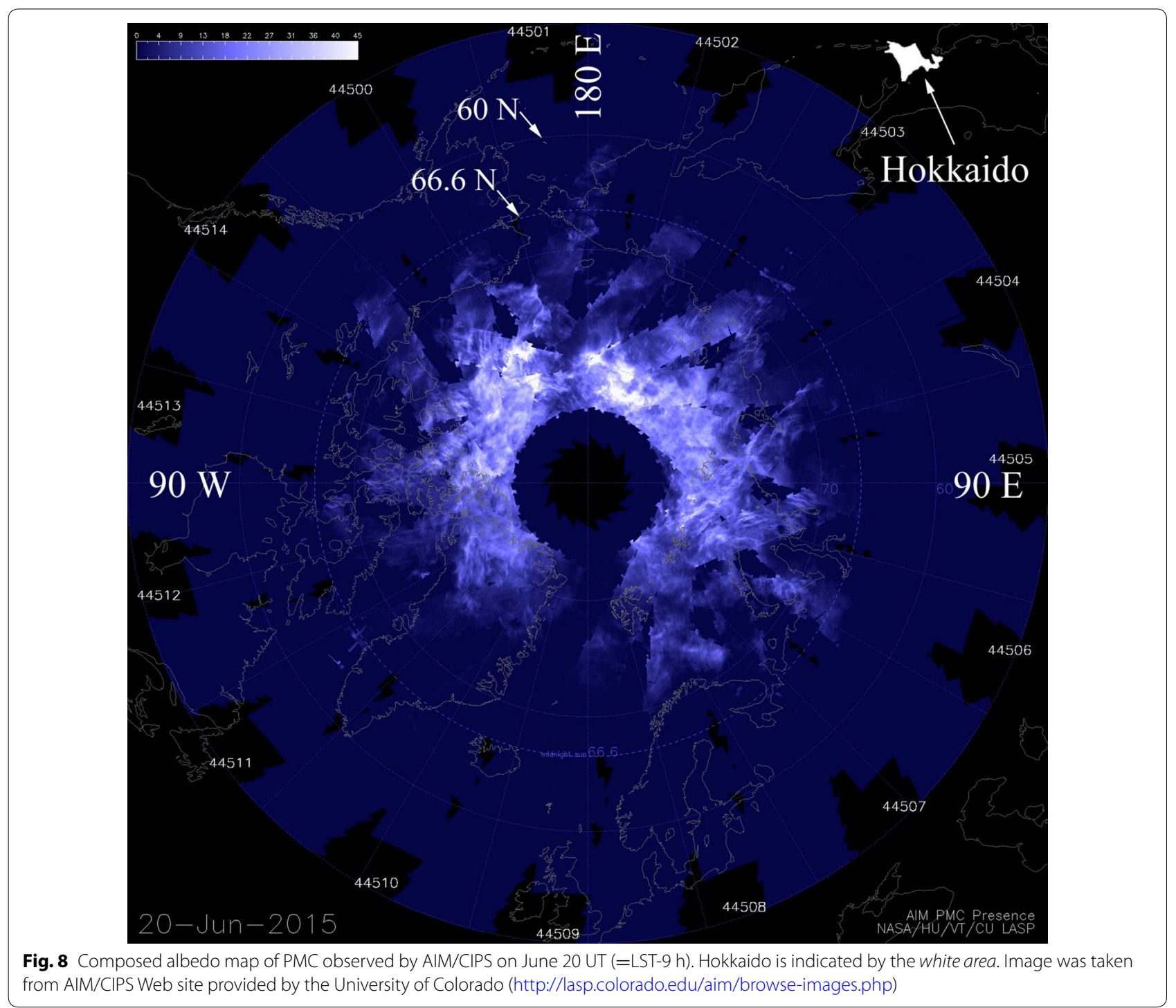

\section{Conclusion}

Simultaneous images of a luminous cloud from five sites in Hokkaido, Japan $\left(43.17-45.36^{\circ} \mathrm{N}\right)$, were successfully observed using digital cameras in the early hours of the early morning on June 21,2015 . The exact altitude $\left(Z_{\mathrm{s}}=83.9 \pm 0.1 \mathrm{~km}\right)$ and spatial distribution (47.5$50.0^{\circ} \mathrm{N}$ and $143.0-147.5^{\circ} \mathrm{E}$ ) of the cloud were estimated by triangulation and image correlation methods. This is the first NLC event captured and robustly identified in Japan.

Because this is the first NLC event recorded in Japan, an anomaly in the upper mesospheric temperature of the northern hemispheric summer in 2015 was examined by using AURA satellite data. However, no remarkable trends in temperature variations relative to other years were found. By comparing the meridional wind and cloud distribution data from the AIM satellite with our data, this single event is considered to be the result of advection of the NLC due to continuous southward winds (duration $\sim 6 \mathrm{~h}$ ) from a higher-latitude (i.e., colder) region.

Weather conditions during the NLC season were also investigated as one of the possible reasons why the NLC had not previously been sighted in Hokkaido (or elsewhere in Japan). A comparison between past NLC periods and records of sky conditions in the northernmost part of Hokkaido (Wakkanai) archived by JMA shows that only $10.8 \%$ (3.1\%) of morning (night) twilight times were clear on the days of MSE events from 2009 to 2015. If days with MSEs are assumed to be potential days for an NLC occurrence in Hokkaido, bad weather conditions for sky-watching cannot be ruled out as a possible explanation. 
Although advection is an important mechanism for an NLC occurrence in a mid-latitude region, similar to a subpolar region, the question of local formation by transient cooling due to small-scale disturbances, such as gravity waves, is still an open question. Simultaneous observation of the local temperature around the mesopause region and continuous imaging from more locations in Hokkaido to increase the opportunities of NLC detection are strongly desired to understand NLC appearances in the mid-latitude region of Japan.

\begin{abstract}
Abbreviations
AIM: the Aeronomy of Ice in the Mesosphere; CIPS: the cloud imaging and particle size; FOV: field of view; JMA: Japan Meteorological Agency; MF: middle frequency; MLS: microlimb sounder; MOS: Moshiri observatory; MSE: mesosphere summer echo; NLC: noctilucent cloud; NASA: National Aeronautics and Space Administration; NICT: National Institute of Information and Communications Technology; NYR: Nayoro observatory; OTR: Otaru; PMC: polar mesospheric cloud; RIK: Rikubetsu observatory; SAR: Sarobetsu observatory; WAK: Wakkanai observatory.
\end{abstract}

\section{Authors' contributions}

$\mathrm{HS}$ carried out the analysis and image processing of NLC images. HS, KS, NN TO, MKE, MK, TK, YM and YF contributed to data collection and scientific analysis. All authors contributed to manuscript preparation and read and approved the final manuscript.

\section{Author details}

${ }^{1}$ Meiji University, Kawasaki, Kanagawa, Japan. ${ }^{2}$ Komazawa University, Setagaya, Tokyo, Japan. ${ }^{3}$ Institute for Space-Earth Environmental Research, Nagoya University, Nagoya, Aichi, Japan. ${ }^{4}$ National Institute of Information and Communications Technology, Koganei, Tokyo, Japan. ${ }^{5}$ National Institute of Polar Research, The Graduate University for Advanced Studies (SOKENDAI), Tokyo, Japan. ${ }^{6}$ Japan Agency for Marine-Earth Science and Technology, Yokosuka, Kanagawa, Japan. ${ }^{7}$ Institute of Low Temperature Science, Hokkaido University, Sapporo, Hokkaido, Japan.

\section{Acknowledgements}

The authors acknowledge the support from the AURA and AIM projects and the MLS and CIPS teams for providing the temperature and cloud imaging data. The authors also thank Nayoro City and Monbetsu City for providing space for monitoring cameras. The authors would also like to express gratitude to Mr. Masamichi Shisa for providing precious NLC photographs taken from Otaru as a scientific contribution. The authors thank Dr. Kaori Sakaguchi for her assistance in data collection. Operation of the digital camera at Moshiri Observatory was carried out by the joint research program of the Solar-Terrestrial
Environment Laboratory (presently Institute for Space-Earth Environmental Research), Nagoya University.

\section{Competing interests}

The authors declare that they have no competing interests.

Received: 23 June 2016 Accepted: 1 November 2016

Published online: 14 November 2016

\section{References}

Gadsden M, Schröder W (1989) Noctilucent clouds. Physics and chemistry in space planetology, vol 18. Springer, Berlin, pp 1-12

Gerding M, Höffner J, Rauthe M, Singer W, Zecha M, Lübken FJ (2007) Simultaneous observation of noctilucent clouds, mesospheric summer echoes, and temperature at a midlatitude station (54 N). J Geophys Res Atmos 112(D12). doi:10.1029/2006JD008135

Kinoshita T, Murayama Y, Kawamura S (2015) Tidal modulations of mesospheric gravity wave kinetic energy observed with MF radar at Poker Flat Research Range, Alaska. J Geophys Res Atmos 120:6379-6390. doi:10.100 2/2014JD022647

Ogawa T, Kawamura S, Murayama Y (2011) Mesosphere summer echoes observed with VHF and MF radars at Wakkanai, Japan (45.4N). J Atmos Sol Terr Phys 73(14):2132-2141

Russell JM III, Bailey SM, Horányi M, Gordley LL, Rusch DW, Hervig ME, Thomas GE, Randall CE, Siskind DE, Stevens MH, Summers ME, Taylor MI, Englert CR, Espy PJ, McClintock WE, Merkel AW (2009) Aeronomy of Ice in the Mesosphere (AIM) Mission: overview and early science results. J Atmos Sol Terr Phys 71:316-330

Schwartz MJ, Lambert A, Manney GL, Read WG, Livesey NJ, Froidevaux L, Ao CO, Bernath PF, Boone CD, Cofield RE, Daffer WH, Drouin BJ, Fetzer EJ, Fuller RA, Jarnot RF, Jiang JH, Jiang YB, Knosp BW, Krüger K, Li J-LF, Mlynczak MG, Pawson S, Russell JM III, Santee ML, Snyder WV, Stek PC, Thurstans RP, Tompkins AM, Wagner PA, Walker KA, Waters JW, Wu DL (2008) Validation of the Aura Microwave Limb Sounder temperature and geopotential height measurements. J Geophys Res 113:D15S11. doi:10.1 029/2007JD008783

Suzuki H, Chino H, Sano Y, Kadokura A, Ejiri MK, Taguchi M (2015) Imagingbased observations of low-latitude auroras during 2001-2004 at Nayoro, Japan. Earth Planets Space 67(1):1-11. doi:10.1186/s40623-015-0278-z

Taylor MJ, Hapgood MA (1990) On the origin of ripple-type wave structure in the $\mathrm{OH}$ nightglow emission. Planet Space Sci 38(11):1421-1430

Taylor MJ, Gadsden M, Lowe RP, Zalcik MS, Brausch J (2002) Mesospheric cloud observations at unusually low latitudes. J Atmos Sol Terr Phys 64(8):991-999

von Zahn U, Bremer J (1999) Simultaneous and common volume observations of noctilucent clouds and polar mesosphere summer echoes. Geophys Res Lett 26(11):1521-1524. doi:10.1029/1999GL900206

\section{Submit your manuscript to a SpringerOpen ${ }^{\circ}$ journal and benefit from:}

- Convenient online submission

- Rigorous peer review

- Immediate publication on acceptance

- Open access: articles freely available online

- High visibility within the field

- Retaining the copyright to your article

Submit your next manuscript at $\boldsymbol{\nabla}$ springeropen.com 